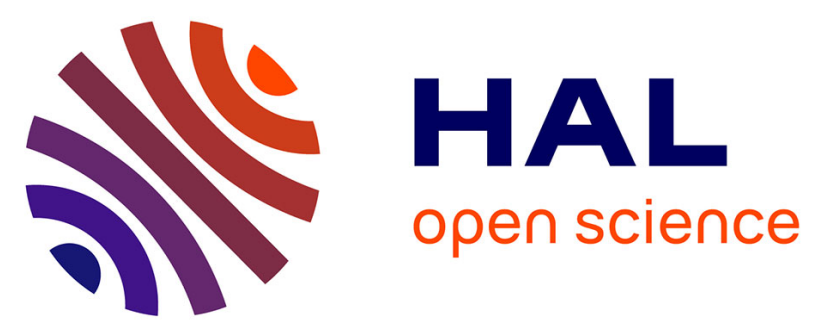

\title{
Crystallization and sintering of borosilicate bioactive glasses for application in tissue engineering
} M. Fabert, N. Ojha, E. Erasmus, M. Hannula, M. Hokka, J. Hyttinen, J. Rocherullé, I. Sigalas, J. Massera

\section{- To cite this version:}

M. Fabert, N. Ojha, E. Erasmus, M. Hannula, M. Hokka, et al.. Crystallization and sintering of borosilicate bioactive glasses for application in tissue engineering. Journal of materials chemistry B, 2017, 5 (23), pp.4514-4525. 10.1039/c7tb00106a . hal-01559211

\section{HAL Id: hal-01559211}

\section{https://hal-univ-rennes1.archives-ouvertes.fr/hal-01559211}

Submitted on 6 Oct 2017

HAL is a multi-disciplinary open access archive for the deposit and dissemination of scientific research documents, whether they are published or not. The documents may come from teaching and research institutions in France or abroad, or from public or private research centers.
L'archive ouverte pluridisciplinaire HAL, est destinée au dépôt et à la diffusion de documents scientifiques de niveau recherche, publiés ou non, émanant des établissements d'enseignement et de recherche français ou étrangers, des laboratoires publics ou privés. 


\title{
Crystallization and sintering of borosilicate bioactive glasses for application in tissue engineering
}

\author{
M. Fabert ${ }^{a}$, N. Ojha ${ }^{a}$, E. Erasmus ${ }^{b, c, d, e}$, M. Hannula ${ }^{a, f}$, M. Hokka ${ }^{g}$, J. Hyttinen ${ }^{a, f}$, J. Rocherulléi, I. \\ Sigalas ${ }^{c, d}$, J. Massera ${ }^{a, e}$ \\ Typical silicate bioactive glasses are known to crystallize readily during the processing of porous scaffolds. While such \\ crystallization does not fully suppress the bioactivity, the presence of significantly large amounts of crystals leads to a \\ decrease in the rate of reaction of the glass and an uncontrolled release of ions. Furthermore, due to the non-congruent \\ dissolution of silicate glasses, these materials have been shown to remain within the surgical site even 14 years post- \\ operation. Therefore, a need for bioactive materials that can dissolve with higher conversion rates and more effectively \\ are required. Within this work, boron was introduced, in the FDA approved S53P4 glass, at the expense of $\mathrm{SiO}_{2}$. $\mathrm{The}$ \\ crystallization and sintering-ability of the newly developed glasses were investigated by differential thermal analysis. All \\ the glasses were found to crystallize primarily from the surface, and the crystal phase precipitating was dependent upon \\ the quantity of $\mathrm{B}_{2} \mathrm{O}_{3}$ incorporated. The rate of crystallization was found to be lower for the glasses were 25,50 and $75 \%$ of \\ the $\mathrm{SiO}_{2}$ was replaced with $\mathrm{B}_{2} \mathrm{O}_{3}$. These glasses were further sintered into porous scaffolds using simple heat sintering. The \\ impact of glass particles size and heat treatment temperature on the scaffolds porosity and average pore size was \\ investigated. Scaffolds with porosity ranging from 10 to $60 \%$ with compressive strength ranging from 1 to $35 \mathrm{MPa}$, were \\ produced. The scaffolds remained amorphous during processing and their ability to rapidly precipitate hydroxycarbonated \\ apatite was maintained. This is of particular interest in the field of tissue engineering as the scaffolds degradation and \\ reaction was generally faster and offers higher controllability as opposed to current partially/fully crystallized scaffolds \\ obtained from the FDA approved bioactive glasses.
}

\section{Introduction}

As of today, autografts are still the gold standard for the repair of large bone defects. However, with the aging and growing population, the number of surgical intervention to regenerate bone defects are increasing. The limited supply and patient site morbidity is a well-known disadvantage and problem [1-2]. Allografts are an option. However, the limited tissue bank as well as the higher risk for infection and cellular and humoral immune reactions limits their usage [3].

The quest for synthetic biomaterials to replace the autografts is more than two decades old. However, as of today no materials have shown as promising a result as autografts. Q. Chen et al. have reported the optimum characteristic that the synthetic materials should have to find great potential as bone grafts [4]. The bone graft should be a 3D construct (3D scaffold) not only biocompatible, but ultimately biodegradable and osteoconductive with highly interconnected porosity. Pore size should be no less than $100 \mu \mathrm{m}$ to allow cell and fluid penetration as well as angiogenesis. In general, interconnected pores of at least $100 \mu \mathrm{m}$ and an open porosity of over $50 \%$ is considered the minimum requirement for tissue ingrowth [57]. Optimally, the construct should have pores within $100-$ $500 \mu \mathrm{m}$ and an overall porosity of over 90\% [8]. Finally, the construct should have mechanical properties similar to the tissue being replaced and should maintain its mechanical properties until new bone is formed.

One of the most promising materials to fulfill these requirements are bioactive glasses. Bioactive glasses are known to be "class A" biomaterials, i.e. that they can bond to both hard and soft tissue. They have also proven record of being antimicrobial and to promote angiogenesis. However, typical bioactive glasses such as Bioglass ${ }^{\circledR}$ and BonAlive ${ }^{\circledR}$ are prone to crystallization at temperature at which it should be hot formed, inhibiting complete sintering prior to crystallization [9]. It was demonstrated that the optimal sintering temperature for Bioglass ${ }^{\circledR}, 45 \mathrm{~S} 5$, taken as an example, is at around $1050^{\circ} \mathrm{C}$ leading to the formation of a partially, up to fully, crystallized body [10]. The impact of crystallization on the glass' bioactivity is still under debate. Research demonstrated that upon partial to full crystallization the bioactivity reduced in both $45 \mathrm{~S} 5$ and S53P4 [11-12]. Even more, some of the secondary crystalline phase were found to be insoluble in simulated body fluid and TRIS buffer solution [12]. More specifically Peitl et al. demonstrated that, in 45S5, the surface reaction rate is slower when the percentage of crystallization exceed $60 \%$ [11]. It should be kept in mind that, while, this holds true for crystallization of typical bioactive glasses, glass-ceramic with tailored crystal composition, size and density can be produced with bioactivity similar to Bioglass ${ }^{\circledR}$. Biosilicate is one such material showing promising results both in-vitro and in-vivo [13].

As of today, 3D scaffold obtained via thermal bonding [14-15] and polymer foam replication [16-18] can be mainly classified as glass-ceramic. While some researchers have developed scaffolds with high mechanical properties [19], some typical bioactive glasses, even deprived of crystalline phase, do not fully resorb in-vivo. Indeed, taken as example, when the glass S53P4 was placed in benign bone tumor, a randomized 14years follow up study concluded on the reminiscence of glass particles within the surgical site [20]. The dissolution of silicate bioactive glasses is a diffusion process. Therefore, it is likely that the formation of the thick $\mathrm{SiO}_{2}$-rich layer along with the formation and crystallization of hydroxyapatite at the surface of the glass particles will, in turn, lead to the decrease of the glass dissolution rate, as the glass surface is further away from 
the dissolving medium and the diffusion barrier changes. It has to be pointed out that such studies are not available for glasses such as 45S5, having faster dissolution rate, and therefore this statement cannot be generalized to all silicate bioactive glasses.

Thus, it is of tremendous importance to develop new glasses that not only can be sintered into porous scaffolds but that can also convert more completely into hydroxyapatite. Borate and borosilicate glass have been found to be promising materials as their conversion kinetic into hydroxyapatite is faster and more complete than typical silicate glasses [21]. Implantation of boron containing glasses based on the $45 \mathrm{~S} 5$ formulation, were implanted in rat tibia bone marrow and found enhance bone formation, when compared to the pure silicate 45S5 [22]. Furthermore, Yao et al. showed that when substituting all the $\mathrm{SiO}_{2}$ by $\mathrm{B}_{2} \mathrm{O}_{3}$ in glass $13-93$, the crystallization of the glass initiated within the bulk despite surface crystallization being also present in the case of small particle sizes [23]. The promising thermal properties of the borate and borosilicate glasses led to the fabrication of scaffolds. However, in the 1393 glass composition sintering is not typically occurring at the sintering temperature. Therefore the studies clearly show the impact of boron on the dissolution of the materials, conversion into hydroxyapatite and the cell/material interaction. Scaffolds were processed using the foam replica techniques [17-18]. Invitro cell culture showed that silicate and borosilicate bioactive scaffold offered enhanced cell proliferation when compared to the borate glass-scaffolds, whereas, in-vivo, all three group were found to promote bone growth [18]. One of the conclusion from this study was that appropriate replacement of $\mathrm{B}_{2} \mathrm{O}_{3}$ for $\mathrm{SiO}_{2}$ can allow for optimum dissolution/conversion rate and optimum substrates for the repair of bone defects [18]. However, a deeper understanding of the impact of replacing $\mathrm{B}_{2} \mathrm{O}_{3}$ for $\mathrm{SiO}_{2}$, in typical bioactive glasses such as $45 \mathrm{~S} 5$ and S53P4, on the thermal properties (crystallization and sintering) is of paramount importance. The importance lies in defining glasses that can convert fully to hydroxyapatite, while having a dissolution rate similar or faster than Bioglass ${ }^{\circledR}$ (45S5) or BonAlive ${ }^{\circledR}$ (S53P4), keeping in mind that these glasses are not suitable for sintering without any crystallization.

Therefore, in this paper we present a crystallization study of S53P4 analogs where the $\mathrm{SiO}_{2}$ is replace in stages by $\mathrm{B}_{2} \mathrm{O}_{3}$. The glass transition and crystallization temperature were recorded at various heating rates to assess the activation energy for viscous flow, the activation energy for crystallization and $\Delta T$ $\left(\Delta T=T_{x}-T_{g}\right.$ where $T_{x}$ is the temperature of the onset of crystallization and $\mathrm{T}_{\mathrm{g}}$ the glass transition temperature recorded by means of a DTA) which corresponds to the hot forming domain. Crystallization rate, at temperature within the crystallization domain were calculated as a function of boron content. The glasses with the slowest crystallization kinetics were sintered into porous scaffolds at various temperatures (below the onset of crystallization) for three different particles sizes. The amorphous nature of the scaffolds were investigated by XRD. Porous structures were immersed in simulated body fluid to confirm the ability of these materials to convert into hydroxyapatite. The mechanical properties were investigated in compression as a function of immersion time. The results will allow defining materials with high dissolution rate, high conversion into hydroxyapatite and thermal properties enabling heat sintering prior to crystallization. Combined to invitro cell culture data, optimum glass composition for bone tissue engineering can be developed.

\section{Experimental section}

Glass processing: The nominal oxide compositions of the experimental glasses in mol\% are (53.85-x) $\mathrm{SiO}_{2}-\mathrm{xB}_{2} \mathrm{O}_{3}-$ $22.66 \mathrm{Na}_{2} \mathrm{O}-1.72 \mathrm{P}_{2} \mathrm{O}_{5}-21.77 \mathrm{CaO}$ with $x$ varying from 0 to 53.85 . The glasses were melted from batches containing mixtures of sand $\left(99.4 \%\right.$ pure $\mathrm{SiO}_{2}$ ), and analytical grades of $\mathrm{Na}_{2} \mathrm{CO}_{3}$, $\mathrm{H}_{3} \mathrm{BO}_{3}, \mathrm{CaCO}_{3}$, and $\mathrm{CaHPO}_{4} \cdot 2 \mathrm{H}_{2} \mathrm{O}$. The glasses were coded according to the $\mathrm{B}_{2} \mathrm{O}_{3} /\left(\mathrm{SiO}_{2}+\mathrm{B}_{2} \mathrm{O}_{3}\right)$ ratio content: $\mathrm{BO}$ (S53P4), $\mathrm{B} 25, \mathrm{~B} 50, \mathrm{~B} 75$ and $\mathrm{B} 100$. The glasses were melted in air in a platinum crucible at temperature from 1000 to $1400{ }^{\circ} \mathrm{C}$ for $3 \mathrm{~h}$ depending on the boron content. After casting in a pre-heated cylindrical $(\varnothing=10 \mathrm{~mm})$ graphite mold, the glasses were annealed overnight at $40^{\circ} \mathrm{C}$ below their respective $\mathrm{T}_{\mathrm{g}}$ and then allowed to cool slowly to room temperature within the annealing furnace. The obtained rods were then crushed into powders within 3 particle size ranges $<50 \mu \mathrm{m}, 250-500 \mu \mathrm{m}$ and $>500 \mu \mathrm{m}$.

Thermal properties: The glass transition temperature $T_{g}$ and the crystallization temperature $T_{p}$ of the glasses were determined using differential thermal analysis (SDTA, Netzsch F1 JUPITER ${ }^{\mathrm{e}}$ ) at a heating rate of $5,10,15$ and $20^{\circ} \mathrm{C} / \mathrm{min}$. The measurements were performed on $30 \mathrm{mg}$ samples with the particle size of 250-500 $\mu \mathrm{m}$ in platinum pans in an $\mathrm{N}_{2}$ atmosphere. The glass transition temperature $T_{g}$ was taken at the inflection point of the first endotherm, obtained by taking the first derivative of the DTA curve; $T_{p}$ was taken at the maximum of the exothermic peak.

The activation energies associated with the glass transition temperature $E_{a}$ and the crystallization peak $E_{c}$ were determined by measuring $T_{g}$ and $T_{p}$, respectively, at different heating rates and then applying the Kissinger equation [24]:

$\ln \left(\frac{q}{T_{s}^{2}}\right)=-\frac{E_{a}}{R T_{g}}+$ Constant, eq. (1)

where $q$ is the heating rate, $T_{g}$ is the glass transition temperature measured with heating rates of $5^{\circ}, 10^{\circ}, 15^{\circ}$, and $20^{\circ} \mathrm{C} / \mathrm{min}$, and $R$ is the gas constant. To determine $E_{c}$, Equation (2) was modified by replacing $T_{g}$ by $T_{p}$. The activation energy for the glass transition temperature is often associated to the activation for viscous flow [25]. When using the Kissinger equation for such calculation one should keep in mind that other more sophisticated method exists [26]. However, despite the assumption on the temperature integral of the Kissinger equation such method has been found to be reliable in a wide range of composition and thermally activated processes measured by DTA [26]. A complete derivation of the Kissinger equation, for non-isothermal glass transition measurement can be found in [27]. The Kissinger 
equation is known to also have limitation when used to describe the activation energy of crystallization. Indeed, such method is only valid in the case of needle-like surface crystallization $[9,28]$. While other method are always tested simultaneously, as in [28] only the Kissinger equation is reported when 1) the values obtained with other, less restrictive techniques are similar, and 2) when surface crystallization is effectively the primary crystal growth in the studied material.

Thermal treatments were performed on $1 \mathrm{~cm}$ glass cubes placed on a platinum holder in a preheated furnace. The glasses were subjected to heat treatment under a flow of $\mathrm{N}_{2}$ for various times and temperatures. The heating rate employed was $20{ }^{\circ} \mathrm{C} / \mathrm{min}$ and the temperatures for the heat treatments were $\mathrm{T}_{\mathrm{p}}-60^{\circ} \mathrm{C}, \mathrm{T}_{\mathrm{p}}-40^{\circ} \mathrm{C}$, and $\mathrm{T}_{\mathrm{p}}-20^{\circ} \mathrm{C}$. $\mathrm{T}_{\mathrm{p}}$ is the maximum of the exothermic peak in the DTA curve recorded at $20^{\circ} \mathrm{C} / \mathrm{min}$ for the powder with size $250-500 \mu \mathrm{m}$. The heat treatment duration was calculated from the time at which the sample was introduced in the furnace. After the treatment, the samples were cooled rapidly in static air.

Scaffold processing and characterization: The scaffolds were processed by loosely placing glass particles into a stainless steel mold, and shaking to obtained particles rearrangement. Sintering was conducting at various temperatures (between 570 and $620^{\circ} \mathrm{C}$ ), depending on the glass composition. The sintering was conducted in air, at a heating rate of $20^{\circ} \mathrm{C} / \mathrm{min}$ and holding time of one hour at the sintering temperature. The porous bodies obtained were characterized by XRD to see is crystals have developed during processing. The porosity of the bodies were quantified by measuring the samples dimension and weight and using $\mu \mathrm{CT}$. In-vitro properties in SBF and mechanical properties in compression as a function of immersion time were also assessed. The samples were dried before mechanical testing.

Porosity analysis was conducted using micro-computational tomography $(\mu \mathrm{CT})$. MicroXCT-400 (Carl Zeiss X-ray Microscopy, Inc., Pleasanton, USA) was used with tube voltage $140 \mathrm{kV}$ and current $71 \mu \mathrm{A}$. Pixel size was $5.6 \mu \mathrm{m}$. Porosity analysis was done with Fiji [29] using BoneJ [30] plugin. $\mu \mathrm{CT}$ visualizations were done with Avizo 9.1 (FEI Visualization Sciences Group)

Degradation tests were conducted on porous scaffolds ( $\sim \mathrm{mm}$ diameter and $8 \mathrm{~mm}$ height, as measured by means of a caliper) by soaking them in SBF for various time intervals $(6,24,48,72$, 168 and 336 hours). SBF buffer solution was prepared according to the protocol described by Kokubo and co-workers [31] at $37^{\circ} \mathrm{C}$ and $\mathrm{pH}$ 7.4. Three to four parallel samples were placed in a shaking incubator at $37^{\circ} \mathrm{C}$.

After each immersion time point, the $\mathrm{pH}$ of the SBF solutions was measured with calibrated $\mathrm{pH}$ meter (Metler Toledo) at 37 ${ }^{\circ} \mathrm{C} .5 \mathrm{~mL}$ of the immersion solution was diluted in $45 \mathrm{~mL}$ of DI water. The IR absorption spectra of the glasses were recorded using Fourier transform infra-red spectroscopy (PerkinElmer Spectrum One FT-IR) in attenuated total reflectance (ATR) mode on powdered glasses. All spectra were recorded within the range $600-4000 \mathrm{~cm}^{-1}$, corrected for Fresnel losses and normalized to the absorption band showing the maximum intensity

The XRD analysis was carried out on the powder samples with the Panalytical EMPYREAN multipurpose X-Ray Diffractometer using nickel filtered copper K-Alpha radiation. The scaffolds were crushed and the powder was gently pressed into the sample holder, and the spectra was obtained using the BraggBrentano geometry and by rotating the sample holder around the Phi-axis at a constant speed of 16 revolutions per minute during the scan.

The compression strength of the samples was measured using an Instron mechanical tester with displacement of $0.5 \mathrm{~mm} / \mathrm{min}$ and a load cell of $500 \mathrm{~N}$. The values are presented as the average of three parallel samples.

\section{Results}

Glass crystallization: Figure 1 presents the DTA thermograms of the glasses, whereas the characteristic temperatures are listed in Table 1 . With an increase in $\mathrm{B}_{2} \mathrm{O}_{3}$ content the glass transition temperature, $T_{g}$, and the onset and maximum crystallization temperatures, $T_{x}$ and $T_{p}$, decreased. $\Delta T=T_{x}-T_{g}$ was calculated and is considered to represent the hot working domain. The larger the $\Delta \mathrm{T}$ the more likely the glass can be hot formed (sintered or drawn into fibers) without undergoing crystallization. Here $\Delta T$ presents a maximum of $165^{\circ} \mathrm{C}$ for glass B50. The intensity of the crystallization peak was found to decrease for $\mathrm{SiO}_{2}$ substitution up to $50 \%$ and then increases for higher $\mathrm{B}_{2} \mathrm{O}_{3}$ content. In Table 1 the temperature $\mathrm{T}_{\mathrm{p}}$ for the glass $\mathrm{B} 50$ is not reported as it was found to be highly inaccurate due to its very low intensity. Furthermore, it appears that the crystallization peak is overlapping with the beginning of the melting process. It is interesting to note that the glass S53P4, from [9] only present one crystallization peak. B25 and B100 exhibit two crystallization peaks while B75 only present one peak related to the glass crystallization.

The activation energy for viscous flow and crystallization were calculated using the equation proposed by Kissinger [24] and are reported in Table 2. The activation for viscous flow exhibits a minimum for B25 / B50 and then increases slightly with increasing the $\mathrm{B}_{2} \mathrm{O}_{3}$ content. All glasses show similar activation energy for crystallization.

In typical crystallization kinetics studies the Johnson-MehlAvrami (JMA) exponent as well as the JMA model validity are defined as in [9]. However, here complex crystallization mechanism were already evidenced by DTA analysis. As shown in Figure 2, presenting the crystallization peak of glass B25 at various heating rates, the ratio between the two crystallization peaks changed as a function of heating rate. Furthermore, the overlap of more than one crystal phase inhibited proper calculation of the JMA exponent and JMA model validity.

The fragility parameter of the studied glass was calculated using the following equation [32]: 
$F_{\mathrm{i}}=\frac{E_{a}}{R T_{g} \operatorname{Ln}(0)}$

Where $E_{a}$ is the activation energy for viscous flow, $R$ the gas constant, $\mathrm{T}_{\mathrm{g}}$ the glass transition at a heating rate $\mathrm{Q}$. The calculated fragility parameter, taken at $q=10{ }^{\circ} \mathrm{C} / \mathrm{min}$, are reported in Table 2 . The fragility parameter presents a minimum for the glass B25.

To further understand the crystallization occurring in the investigated glasses, glass monoliths were heat treated at $\mathrm{Tp}$ $20{ }^{\circ} \mathrm{C}, \mathrm{Tp}-40{ }^{\circ} \mathrm{C}$ and $\mathrm{Tp}-60{ }^{\circ} \mathrm{C}$ for various time. To facilitate the analysis the heat treated glasses were embedded in a resin and polished to image crystals that could have grown at the surface or in the volume of the glass. Figure 3 presents the optical micrograph of the glass B100, taken as an example. As seen in the Figure, the crystallization is seen as a layer at the surface of the glass. With no crystals present within the volume of the glass. Figure 4 presents the layer thickness measured by optical microscopy, as a function of heat treatment time at $\mathrm{Tp}-20{ }^{\circ} \mathrm{C}, \mathrm{Tp}-40{ }^{\circ} \mathrm{C}$ and $\mathrm{Tp}-60{ }^{\circ} \mathrm{C}$. The layer was found to increase in thickness with increasing time and/or temperature. The slope of each individual curve corresponds to the speed of crystallization at this particular temperature. The speeds of crystallization are reported in Table 3 for all borosilicate glasses. The glass S53P4 was not analyzed as it was already found that this glass crystallizes too rapidly to enable any hot forming below the crystallization temperature [9].

All partially to fully crystallized glasses were analyzed using XRD. From past research on the glass S53P4 it was found that two crystal phase forming compounds in that glass were $\mathrm{Na}_{2} \mathrm{CaSi}_{2} \mathrm{O}_{6}$ and $\mathrm{Ca}_{4} \mathrm{Na}_{2} \mathrm{P}_{2} \mathrm{SiO}_{12}[9,12]$. The glass $\mathrm{B} 25$ was found to crystallize $\mathrm{Na}_{2} \mathrm{CaSi}_{2} \mathrm{O}_{6}$ and $\mathrm{CaNa}_{3} \mathrm{~B}_{5} \mathrm{O}_{10}$. The glass $\mathrm{B} 50$ crystallized $\mathrm{CaNa}_{3} \mathrm{~B}_{5} \mathrm{O}_{10}$ primarily and $\mathrm{Na}_{4} \mathrm{Ca}_{4} \mathrm{Si}_{6} \mathrm{O}_{18}$ / $\mathrm{Na}_{2} \mathrm{CaSi}_{3} \mathrm{O}_{8}$. In both $\mathrm{B} 25$ and $\mathrm{B} 50$ it is highly probable that a minor phase containing $\mathrm{P}$ was present. Lastly, B75 and B100 crystallized primarily $\mathrm{CaNa}_{3} \mathrm{~B}_{5} \mathrm{O}_{10}$ and $\mathrm{Na}_{2} \mathrm{~B}_{4} \mathrm{O}_{7}$, most likely with a third phase containing $\mathrm{P}$.

Glass sintering: Simple heat sintering was applied to the glasses labelled B25, B50 and B75. The sintering was conducted at various temperature and for three particles sizes $(<125 \mu \mathrm{m}, 250-500 \mu \mathrm{m}$ and $>500 \mu \mathrm{m})$.

Figure 5 show the $\mu \mathrm{CT}$ images and pore size distribution obtained for the glass B50 (particle size 250-500 $\mu \mathrm{m}$ ) sintered at 570, 580 and $590{ }^{\circ} \mathrm{C}$. Despite the overall porosity decreasing with increasing temperature, the average pore size remains in the 100-150 $\mu \mathrm{m}$ range. As expected with decreasing the particles size, the average pore size was found to decrease to below $100 \mu \mathrm{m}$, while with increasing particles size the average pore size was between 200-250 $\mu \mathrm{m}$.

Figure 6 present the porosity of the produced scaffolds processed at various temperature and for each particle size in the case of the glass B25 a), B50 b) and B75). With increasing the sintering temperature, the overall porosity of the scaffolds decreased. For all compositions the overall porosity could be adjusted between 10 to $60 \%$.
Figure 7 presents the compressive strength of glass B25 a), B50 b) and $B 75 \mathrm{c}$ ) as a function of porosity for porous scaffold obtained from particles with size ranging from 250 to $500 \mu \mathrm{m}$. Overall the mechanical properties (compressive strength) varied from (35 \pm 3 ) to $(1 \pm 2) \mathrm{MPa}$. Overall the compressive strength decreases with increasing the porosity almost linearly. Not shown here, when sintering smaller particles, the compressive strength was found to increase whereas when sintering larger particles, the compressive strength decreased. As shown in Figure $7 \mathrm{~d}$ ), which shows the compressive strength as a function of porosity for the glass B25, B50 and B75 sintered using particles size $250-500 \mu \mathrm{m}$, regardless of the glass composition at equal porosity we see similar compressive strength within the accuracy of the measurements.

Porous scaffolds obtained from particles ranging from 250-500 $\mu \mathrm{m}$ with $50 \%$ overall porosity were immersed in simulated body fluid. The change in $\mathrm{pH}$ was recorded as a function of immersion time and is presented in Figure 8. With an increase in the immersion time the $\mathrm{pH}$ increased for all sample. The $\mathrm{pH}$ was highest for the $\mathrm{B} 50$ scaffolds whereas it was lower for B75. The surface modification occurring at the particle surface was assessed at various immersion times using FTIR-ATR. The FTIR spectra are presented in Figure 9. The samples were crushed and the powder was analyzed prior to the immersion test (Figure 9a) as reference. All spectra were background corrected and normalized to the band with maximum intensity at $930 \mathrm{~cm}^{-1}$. As explained in [33], the spectra of pure silicate glasses show absorption bands also at 748, 930, $1023 \mathrm{~cm}^{-1}$ and in the $1400-1515 \mathrm{~cm}^{-1}$ region. The band at $930 \mathrm{~cm}^{-1}$ can be attributed to $\mathrm{Si}_{-} \mathrm{O}^{-}$in $\left[\mathrm{SiO}_{4}\right]$ and the band peaking at $1023 \mathrm{~cm}^{-1}$ to $\mathrm{Si}-\mathrm{O}-\mathrm{Si}$ asymmetric stretching in $\left[\mathrm{SiO}_{4}\right]$ units [34-36]. The band at $748 \mathrm{~cm}^{-1}$ is due to Si-O bending [37]. The band located within $1400-1515 \mathrm{~cm}^{-1}$ is related to carbonate in the glass structure [38]. With increasing the boron content:

i) a band at $1401 \mathrm{~cm}^{-1}$ appears which shift to $1380 \mathrm{~cm}^{-1}$. The band was attributed to $\left[\mathrm{BO}_{3}\right]$ triangles [39-40].

ii) a shoulder at $1337 \mathrm{~cm}^{-1}$ and a band at $1227 \mathrm{~cm}^{-1}$ appeared. The shoulder was attributed to borate triangles $\left[\mathrm{BO}_{3}\right]$ and the band to $\left[\mathrm{BO}_{2} \mathrm{O}^{-}\right][39-40]$.

iii) the two bands at 930 and $1023 \mathrm{~cm}^{-1}$ broadened to form one large band for full $\mathrm{SiO}_{2}$ substitution. The broad band was attributed to a combination of vibration modes from $\left[\mathrm{BO}_{4}\right]$ units at $875 \mathrm{~cm}^{-1}$, $\mathrm{B}-\mathrm{O}-\mathrm{M}$ in the $\sim 992 \mathrm{~cm}^{-1}$ range as well as B-O-Si and B-O-B linkages [39-41].

iv) the band at $748 \mathrm{~cm}^{-1}$ related to $\mathrm{Si}-\mathrm{O}$ bending decreased and a new band formed at $715 \mathrm{~cm}^{-1}$ and grew in intensity. This new band was attributed to B-O-B bending [39-41].

Upon immersion of the scaffold for $6 \mathrm{~h}$ in the SBF solution (Figure 9b) structural changes are noticed. The main band at $930 \mathrm{~cm}^{-1}$ decreases in intensity. The change is more drastic in the case of the B75 glass. With extending the immersion time up to $168 \mathrm{~h}$ (Figure 9c) a sharp peak at $1019 \mathrm{~cm}^{-1}$ and at $890 \mathrm{~cm}^{-1}$ appeared and grew in intensity. The bands in the low wavenumber range disappear and the band in the $1300-1500 \mathrm{~cm}^{-1}$ range became a doublet. 
The compressive strength of the porous scaffolds was tested as a function of the reminiscence time in the SBF as shown in Figure 10. The compressive strength drastically decreases already after $6 \mathrm{~h}$ of immersion after which it remains constant within the accuracy of the measurement.

\section{Discussion}

Glass crystallization: The more loosely packed glass network obtained when $\mathrm{SiO}_{2}$ is replaced with $\mathrm{B}_{2} \mathrm{O}_{3}$ led to a decrease in the $T_{g}, T_{x}$ and $T_{p}$ (Figure 1 and Table 1). This is in agreement with previous studies which showed that $\mathrm{B}_{2} \mathrm{O}_{3}$ can be used to decrease the $T_{g}$ and forming temperatures of glasses [42]. However, it is interesting to note that the glasses B25 and B100 clearly show two crystallization peaks while S53P4 and B75 only exhibit one crystallization peak. It is known that the glass S53P4 (B0) despite possessing only one crystallization peak, upon crystallization, formed two crystals with distinct composition $[9,12]$. It is then likely that all borosilicate glasses studied here crystallize by forming at least two crystal phases. Another interesting fact is that the intensity of the crystallization peak decreased drastically up to glass $\mathrm{B} 50$ and then increased. This may indicate that, in mixed $\mathrm{B}_{2} \mathrm{O}_{3} / \mathrm{SiO}_{2}$ glass the crystallization is less prone to occur upon heating. It is generally accepted that a $\Delta \mathrm{T}>100^{\circ} \mathrm{C}\left(\Delta \mathrm{T}=\mathrm{T}_{\mathrm{x}}-\mathrm{T}_{\mathrm{g}}\right)$ leads to glasses that can be shaped via viscous flow to form fibers and/or porous sintered structures [43]. However, for some glasses with rapid crystallization kinetics and high activation energy for viscous flow even a $\Delta \mathrm{T}>100^{\circ} \mathrm{C}$ may not be sufficient as it is the case for the glass S53P4 $[9,12]$. As the $\Delta T$ is not a sufficient parameter to infer the hot forming ability of a glass, the activation energy for viscous flow $\left(E_{a}\right)$ and the fragility parameter $\left(F_{i}\right)$ of the glasses were calculated (Table 2). Glass S53P4 is found to possess high $E_{a}$ and $F_{i}$ which, despite its large $\Delta \mathrm{T}$, indicates that crystallization will happen prior to viscous flow. At the opposite, the glass B100 possess a lower $E_{a}$ and $F_{i}$ than glass S53P4, however the $\Delta \mathrm{T}$ is rather low and close to $100{ }^{\circ} \mathrm{C}$, which also tends to indicate that this glass is not suited for shaping at temperature below its crystallization. Glasses B25, B50, and B75, exhibit a high $\Delta T$ while possessing significantly lower $E_{a}$ and $F_{i}$ than glass S53P4. This is promising result in terms of the processing of scaffolds via heat sintering.

Table 3 reports the crystallization rate, obtained from linear regression of the curves shown in Figure 4, at temperature within the crystallization domain. As expected an increase in the crystallization rate is seen with increasing heat treatment temperature. More interestingly, the glasses B25, B50 and B75 were found to have crystallization temperatures far lower than the B100 glass. Here, the crystallization rate of the glass S53P4 was not measured as it was previous reported that this glass exhibits crystallization kinetics that inhibit proper sintering of particles into amorphous scaffolds [9]. This result supports the previous statement that borosilicate glasses offer enhanced hot forming capability than silicate or borate glass equivalents. However, regardless of the composition, all glasses were found to crystallize primarily from the surface (Figure 3). All glasses. It is also noteworthy that the thickness of the formed layer is linear with time which indicate a surface controlled crystallization rather than a diffusion controlled crystallization [44]. This indicates that the attachment of atoms at the surface of the crystals and the movement of atoms, in the vicinity of the crystals, to the crystals occurs at a faster rate than transport / diffusion of atoms to the crystals [45]. All materials precipitated at least two crystal phase as evidenced by XRD. The primary crystal phase precipitated in the glass B25 are highly dependent of the heating cycle used as shown in Figure 2.

Glass sintering: Glass particles sintering were conducted on three particles size and at various temperatures. As expected, with increasing sintering temperature the overall pore size decreased [46]. By decreasing the particles size for sintering the average pore size decreased as smaller particles were able to cluster together sinter faster than their larger counterparts [47]. This is corroborate by the higher densities of construct produced from smaller verses larger particles when sintered at the same temperature. As shown in Figure $6, \mu \mathrm{CT}$ shows that the scaffolds produced using particle sizes between $250-500 \mu \mathrm{m}$ leads to an average pore size in the range $100-150 \mu \mathrm{m}$. Such porosity, if open, is thought sufficient to support cell migration and vascularization [48-49]. Scaffolds obtained from smaller particles size led to smaller pores below this range. Despite possessing higher mechanical strength these materials are not suited for tissue engineering as it is likely that vascularization and cell transport will be inhibited. Average pore sizes larger than $100 \mu \mathrm{m}$ are often considered to be better in tissue engineering [4]. However, as seen in this study, the increase in pore size and overall porosity also leads to a drastic decrease in the mechanical properties, such as the compressive strength (Figure 7). For this reason, for simple heat sintering, particle size in the 250 $500 \mu \mathrm{m}$ range seems to be better suited for the processing of the scaffolds. For such particles sizes the mechanical strength was found to be dependent only upon the pore size and not on the glass composition itself (Figure 7d). Indeed, from figure 7d, it appears that, at similar porosity, all the scaffolds have comparative compression strength, regardless of the glass composition, within the accuracy of the measurement. The scaffolds obtained from particle sizes ranging from $250-500 \mu \mathrm{m}$, sintered at the highest temperature, i.e. $620{ }^{\circ} \mathrm{C}$ for $\mathrm{B} 25$ and $600{ }^{\circ} \mathrm{C}$ for $\mathrm{B} 50$ and $\mathrm{B} 75$ were analyzed by XRD, no evident signs of crystallization were observed as seen in Figure 11. Indeed, the XRD pattern clearly shows the amorphous nature of the scaffolds. It can be concluded that, as opposed to typical bioactive silicate glasses with rapid dissolution in-vitro, such as $45 \mathrm{S5}$ and S53P4, borosilicate glasses can be sintered without inducing significant crystallization. XRD analysis was also performed on the scaffolds obtained from the smaller particles size range and did not exhibit any signs of crystallization.

Scaffold with $50 \%$ overall porosity and average pore size between 100 and $150 \mu \mathrm{m}$ were produced. The compressive strength of these scaffolds were found to range between 3 to $5 \mathrm{MPa}$. Such mechanical properties are close to the one for cancellous bone [50]. The ability of these scaffolds to precipitate a hydroxyapatite layer at their surface was investigated using FTIR-ATR. Figure 9 presents the FTIR spectra of the scaffolds prior to immersion, all the absorption bands are related to the vibrations of bridging and non-bridging oxygen in $\left[\mathrm{SiO}_{4}\right]$ units as well as vibrations from $\left[\mathrm{BO}_{3}\right]$ and $\left[\mathrm{BO}_{4}\right]$ units. Upon immersion in simulated body fluid a decrease in the absorption band related to the borate and silicate structure (Figure 9b) could be seen with appearance and increase in intensity of sharp peaks at 1019 and $890 \mathrm{~cm}^{-1}$ (Figure 9c). As seen in [33] this sharp peaks are related to phosphate vibration. More precisely such 
vibration corresponds to phosphate vibration in a hydroxyapatite structure. The doublet seen in the $1300-1500 \mathrm{~cm}^{-1}$, in Figure $9 \mathrm{c}$, is attributed to carbonate vibrations, which further confirms the precipitation of a hydroxycarbonatedapatite [38]. The early reaction of the glass seen in the FTIR spectra may explain the fast decrease in the compressive strength seen in Figure 10. It is interesting to point out that the glass B50 appears to react faster than the glass B25 as evidenced by the higher $\mathrm{pH}$ rise (Figure 8). However, it was expected that the glass B75 would react at an even faster rate as it is well accepted that an increase in the boron content in bioactive glasses leads to an increase in dissolution rate. However, from FTIR results, it is clear that little change occurs at the surface of the scaffolds up to one week of immersion. One explanation for the anomalous behavior of this glass could be that reaction rate was so fast that it led to accumulation of debris in the pores, thus closing the pores and reducing the surface in contact with the solution. The liquid trapped in the scaffold structure will induce degradation of the struts leading to the decrease in the mechanical properties; this was partly confirmed by the EDX/SEM analysis. Scaffold were embedded in resin and polished to reveal the cross section of the scaffolds. Figure 12 presents the SEM images of the B50 scaffold cross section after $0 \mathrm{a}$ ), $24 \mathrm{~h} \mathrm{~b}$ ), $48 \mathrm{~h} \mathrm{c}$ ) and $72 \mathrm{~h} \mathrm{~d}$ ) of immersion. The SEM images clearly exhibit precipitation of a reactive layer at the surface of the particles, within the scaffolds at $48 \mathrm{~h}$ of immersion (as shown by the red arrows in the figure). The reactive layer is better seen in the images at higher magnification (e-f), recorded using backscattering electrons. The layer was not necessarily found to grow thicker with increasing time. However, more particles were found to have a reactive layer at their surface after $168 \mathrm{~h}$ of immersion. The reactive layer was found to be mainly silica rich, as expected from silicate glass dissolution, with a thin layer richer in $\mathrm{Ca}$ and P. SEM images (g-h) presents the surface of the scaffolds immersed for 48 and $72 \mathrm{~h}$ in SBF. Here we can clearly see that nodule like precipitate is present at the surface of the scaffolds. The density of the nodules increased to form a uniform layer after $72 \mathrm{~h}$ of immersion. Similar images were obtained from the B25 scaffolds whereas no layer precipitation could be seen within the B75 scaffolds. The outermost layer formed at the glass particles surface had a $\mathrm{Ca} / \mathrm{P}$ ratio close to 1.67 , as measured by EDX, which confirms the precipitation of a calcium phosphate close to hydroxyapatite within the scaffold structure. The fast degradation of the scaffolds led to a sharp decrease in the mechanical properties already at $6 \mathrm{~h}$ of immersion. The glass B25 was found to maintain higher compressive strength as a function of immersion time, when compared to $\mathrm{B} 50$ and $\mathrm{B} 75$, probably due to the lower reaction rate.

\section{Conclusions}

Typical silicate bioactive glasses, such as S53P4 and 45S5, are known to be prone to crystallization upon heating. Crystallization is also known to reduce or suppress bioactivity. Partial to full substitution of $\mathrm{SiO}_{2}$ with $\mathrm{B}_{2} \mathrm{O}_{3}$ was studied in order to develop new bioactive glasses with optimum thermal processing windows.

While borate glasses were found to not be suited due to their limited hot forming domain, borosilicate glasses were found to possess not only a wide hot forming domain but also a low activation energy for viscous flow. The crystallization rate of these borosilicate glasses was found to be lower than their borate and silicate counterpart. The addition of boron leads to a shift of all characteristic temperatures toward lower temperatures. Up to $50 \% \mathrm{~B}_{2} \mathrm{O}_{3}$ substitution for $\mathrm{SiO}_{2}$ led to the formation of a stronger glass network which is characterize by less variation in viscosity with a small change in temperature.

Amorphous scaffolds were produced with $50 \%$ overall porosity and average pore size of $100-150 \mu m$, with compressive strength within the range of cancellous bone. 25 and $50 \%$ of $\mathrm{SiO}_{2}$ substitution with $\mathrm{B}_{2} \mathrm{O}_{3}$ was found optimal to produce amorphous scaffolds while allowing hydroxycarbonated apatite precipitation within the scaffold structure. Glasses with highest silicate content were found to maintain their mechanical properties for longer immersion times.

The work present shows that substitution of $\mathrm{B}_{2} \mathrm{O}_{3}$ for $\mathrm{SiO}_{2}$ is promising in the field of bone tissue engineering due to their faster precipitation of hydroxycarbonateapaptite compared to typical silicate glasses. This is of particular importance when defining new glasses composition with faster or similar dissolution rate than the typical 4555 bioactive glass developed by L.L. Hench. They can be sintered into porous scaffolds without undergoing crystallization, which, in silicate bioactive glass, decreases the bioactivity and renders the overall scaffold less prone to undergo complete dissolution. Porous scaffolds with a wide range of porosity can be obtained with mechanical properties within the range of cancellous bone at relatively low temperature.

\section{Acknowledgements}

The authors would like to acknowledge the Academy of Finland for Financial support of JM through the Academy Research Fellow program. The Jane and Aatos Erkko Foundation is also greatly acknowledgment for its support through the AGATE project

All authors declare having no conflicts of interest.

\section{References}

1 W.G. De Long, T.A. Einhorn, K. Koval, M. Mckee, W. Smith, R. Sanders, T. Watson, The Journal of Bone and Joint Injury, 89A (2007) 649-658.

2 Q. Fu, E. Saiz, M.N. Rahaman, A.P. Tomsia, Materials Science and Engineering C, 31 (2011) 1245-1256

3 H. Shegarfi, O. Reikeras, Journal of Orthopaedics, 17 (2009) 206-211

4 Q. Chen, J.A. Roether, A.R. Boccaccini, Chapter 6: Tissue Engineering Scaffolds from Bioactive Glass and Composite, ebook "Topics in Tissue Engineering", 4, (2008)

5 Q. Fu, E. Saiz, M.N. Rahaman, A.P. Tomsia, Materials Science and Engineering C: Materials for Biological Applications, 31 (2010) 1245-1256.

6 V. Karageorgiou, Kaplan D., Biomaterials, 26 (2005) 54745491.

7 J.O. Hollinger, J. Brekke, E. Gtiskin, D. Lee, Clinical Orthopaedics and Related Research, 324 (1996) 55-65

8 L.C. Gerhardt and A.R. Boccaccini, Materials 3 (2010) 38673910.

9 J. Massera, S. Fagerlund, L. Hupa, M. Hupa, Journal of the American Ceramic Society, 95 (2012) 607-613..

10 O. Bretcanu, X. Chatzistavrou, K. Paraskevopoulos, R. Conradt, I. Thompson, A.R. Boccaccini, Journal of the European Ceramic Society, 29 (2009) 3299-3306.

11 O. Peitl Filho, G.P. LaTorre, L.L. Hench, Journal of Biomaterials Research, 30 (1996) 509-514.. 
12 S. Fagerlund, J. Massera, N. Moritz L. Hupa, M. Hupa, Acta Biomaterialia, 8 (2012) 2331-2339.

13 A.C.M. Renno, P.S. Bossini, M.C. Crovace, A. Candida, M. Rodrigues, E.D. Zanotto, N.A. Parizotto, Biomedical Research International, (2013) article ID: 141427

14 Q. Fu, M.N. Rahaman, B.S. Bal, W. Huang, D.E. Day, Journal of Biomedical Research A, 82A (2007) 222-229.

15 R.F. Brown, D.E. Day, T.E. Day, S. Jung, M.N. Rahaman, Q. Fu, Acta Biomaterialia, 4 (2008) 387-396

16 Q. Fu, M.N. Rahaman, B.S. Bal, R.F. Brown, D.E. Day, Acta Biomaterialia, 4 (2008) 1854-1864.

17 H. L. Fu, Q. Fu, N. Zhou,W.H. Huang, M.N. Rahaman, D.P. Wang, X. Liu, Materials Science and Engineering C, 29 (2009) 2275-2281.

18 Q. Fu, M.N. Rahaman, H. L. Fu, R.F. Brown, X. Liu, Journal of Biomedical Research A, 95A (2010) 164-171

19 T.S. Huang, M.N. Rahaman, N.D. Doiphode, M.C. Leu, B.S. Bal, D.E. Day, X. Liu, Materials Science and Engineering C, 31 (2011) 1482-1489.

20 N.C. Lindfors, I. Koski, J.T. Heikkilä, K. Mattila, A.J. Aho, Journal of Biomedical Materials Reseasearch B: Applied Biomaterials, 94 (2010) 157-164..

21 W. Huang, D.E. Day, K. Kittiratanapiboon, M.N. Rahaman, Journal of Materials Science: Materials in Medicine, 17 (2006) 583-596.

22 A.A. Gorustovich, J.M. Lopez, M.B. Gugliemotti, R.L. Cabrini, Biomedical Materials 1 (2006) 100-105.

23 A. Yao, M. N. Rahaman, J. Lin, W. Huang, Journal of Materials Science, 42 (2007) 9730-9735.

24 H.E. Kissinger, Analytical Chemistry, 29 (1957) 1702.

25 J.E. Shelby, Introduction of Glass Science and Technology, Royal Society of Chemistry, 2005

26 M.J. Starink, Thermochimica Acta, 404 (2003) 163-176

27 A.A. Soliman, Journal of Thermal Analysis and Calorimetry, 89 (2007) 389-392.

28 J. Massera, M. Mayran, J. Rocherullé, L. Hupa, Journal of Materials Science, 50 (2015) 3091.

29 J. Schindelin, I. Arganda-Carreras, E. Frise, V. Kaynig, M. Longair, T. Pietzsch, S. Preibisch, C. Rueden, S. Saalfeld, B. Schmid, J-Y. Tinevez, D. J. White, V. Hartenstein, K. Eliceiri, P. Tomancak, A. Cardona, Nature Methods 9 (2012) 676-682.

30 M. Doube, M.M. Kłosowski, I. Arganda-Carreras, F. Cordeliéres, R.P. Dougherty, J. Jackson, B. Schmid, J.R. Hutchinson, S.J. Shefelbine, Bone 47 (2010) 1076-1079.

31 T. Kokubo, H. Kushitani, S. Sakka, T. Kitsugi, T. Yamamuro, Journal of Biomedicals Material Research, 24 (1990) 721-734.

32 R. Boomer, K.L. Nagi, C.A. Angell, D.J. Plazek, The Journal of Chemical Physics, 99 (1993) 4201-4206

33 J. Massera, L. Hupa, M. Hupa, Journal of Non-Crystalline Solids, 358 (2012) 2701-2707

34 L. Stoch, M. Środa, Journal of Molecular Structure, 511-512 (1999) 77-84

35 M. Szumera, I. Waclawska, Z. Olenjniczak, Journal of Thermal Analysis Calorimetry, 99 (2010) 879-886

36 G.J. Bentrup, H.M.M. Moawad, L.F. Santos, R.M. Almeida, H. Jain, Journal of the American Ceramic Society, 92 (2009) 249252

37 J. Serra, P. González, S. Liste, C. Serra, S. Chiussi, B. León, M. Pérez-Amor, H.O. Ylänen, M. Hupa, Journal of NonCrystalline Solids, 332 (2003) 20

38 A.C. Queiroz, J.D. Santos, F.J. Monteiro, M.H. Prado da Silva, Materials Characterization, 50 (2003) 197-202

39 P. Pascuta, M. Bosca, S. Rada, M. Culea, I. Bratu, E. Culea, Journal of Optoelectronics and Advanced Materials, 10 (2008) 2416-2419

40 L. Koudelka, P. Mosner, Materials Letters, 42 (2000) 194-199

41 C Gautam, A.K. Yadav, A.K. Singh, International Scholarly Research Network, 2012 (2012) 1-17

42 M. Brink, Journal of Biomedical Material Research, 36 (1997) 109-117
43 J. Massera, J. Remond, J. Musgraves, M.J. Davis, S.T. Misture, L. Petit, K. Richardson, Journal of Non-Crystalline Solids, 356 (2010) 2947-2955

44 S.J. Dillon, M.P. Harmer, Materials Science Forums, 558\&559 (2007) 1227

45 Zeolites and Catalysis, Synthesis, Reactions and Applications. Vol. 1 edited by J. Cejka, A. Corma, S. Zones, WILEY-VCH Verlag GmbH \& Co. KGaA, Weinheim, 2010.

46 A. Latesenko, O. Sych, T. Tomila, Processing and Application of Ceramics 9 (2015) 99-105

47 M.O. Prado, E.D. Zanotto, R. Müller, Journal of NonCrystalline Solids, 279 (2001) 169-78

48 C.M. Murphy, M.G. Haugh, F.J. O’Brien, Biomaterials, 31 (2010) 461-466

49 S. Bose, M. Roy, A. Bandyopadhyay, Trends Biotechnol. 30, 2012, 546-554

50 I. Hvid, P. Christensen, J. Sondergaard, P.B. Christensen, C.G. Larsen, Acta Orthopaedica Scandinavica, 54 (1983) 819-825. 


\begin{tabular}{|c|c|c|c|c|}
\hline & $\begin{array}{c}\mathrm{T}_{\mathrm{g}} \\
\left( \pm 2^{\circ} \mathrm{C}\right)\end{array}$ & $\begin{array}{c}\mathrm{T}_{\mathrm{x}} \\
\left( \pm 2^{\circ} \mathrm{C}\right)\end{array}$ & $\begin{array}{c}\mathrm{T}_{\mathrm{p}} \\
\left( \pm 2^{\circ} \mathrm{C}\right)\end{array}$ & $\begin{array}{c}\Delta \mathrm{T}=\mathrm{T}_{\mathrm{x}}-\mathrm{T}_{\mathrm{g}} \\
\left( \pm 4^{\circ} \mathrm{C}\right)\end{array}$ \\
\hline S53P4 & 552 & 698 & 805 & 146 \\
\hline B25 & 519 & 670 & $755 / 803$ & 151 \\
\hline B50 & 510 & 675 & 724 & 165 \\
\hline B75 & 506 & 651 & 705 & 145 \\
\hline B100 & 505 & 611 & $651 / 697$ & 106 \\
\hline
\end{tabular}

Table 1: Characteristic temperatures of the investigated glasses. 


\begin{tabular}{|c|c|c|c|c|}
\hline & $\begin{array}{c}\mathrm{E}_{\mathrm{a}} \\
\pm 20 \\
(\mathrm{~kJ} / \mathrm{mol})\end{array}$ & $\begin{array}{c}\mathrm{E}_{\mathrm{c} 1} \\
\pm 30 \\
(\mathrm{~kJ} / \mathrm{mol})\end{array}$ & $\begin{array}{c}\mathrm{E}_{\mathrm{c} 2} \\
\pm 30 \\
(\mathrm{~kJ} / \mathrm{mol})\end{array}$ & $\begin{array}{c}\mathrm{F}_{\mathrm{i}} \\
(\mathrm{at} \\
\left.10^{\circ} \mathrm{C} / \mathrm{min}\right)\end{array}$ \\
\hline S53P4 & 816 & 308 & & 59 \\
\hline B25 & 515 & 241 & 238 & 36 \\
\hline B50 & 575 & 250 & & 40 \\
\hline B75 & 776 & 312 & & 46 \\
\hline B100 & 764 & 248 & 149 & 43 \\
\hline
\end{tabular}

Table 2: Activation energy for viscous flow $\left(E_{a}\right)$, crystallization $\left(\mathrm{E}_{\mathrm{c} 1}\right.$ and $\left.\mathrm{E}_{\mathrm{c} 2}\right)$ and fragility parameter of the studied glasses 


\begin{tabular}{|c|c|c|c|}
\hline & $\begin{array}{c}\text { Crystallizati } \\
\text { on speed } \\
@ \mathrm{Tp}-20^{\circ} \mathrm{C} \\
\mu \mathrm{m} / \mathrm{h}\end{array}$ & $\begin{array}{c}\text { Crystallizati } \\
\text { on speed } \\
@ \mathrm{Tp}-40^{\circ} \mathrm{C} \\
\mu \mathrm{m} / \mathrm{h}\end{array}$ & $\begin{array}{c}\text { Crystallizati } \\
\text { on speed } \\
@ \mathrm{Tp}-60^{\circ} \mathrm{C} \\
\mu \mathrm{m} / \mathrm{h}\end{array}$ \\
\hline B25 & $166 \pm 7$ & $100 \pm 5$ & $51 \pm 3$ \\
\hline B50 & $95 \pm 12$ & $72 \pm 11$ & $49 \pm 2$ \\
\hline B75 & ND & $120 \pm 14$ & $55 \pm 9$ \\
\hline $\begin{array}{c}\text { B10 } \\
0\end{array}$ & ND & $449 \pm 28$ & $167 \pm 13$ \\
\hline
\end{tabular}

Table 3: Crystallization rate at $\mathrm{Tp}-20{ }^{\circ} \mathrm{C}, \mathrm{Tp}-40{ }^{\circ} \mathrm{C}$ and $\mathrm{Tp}-60{ }^{\circ} \mathrm{C}$ 


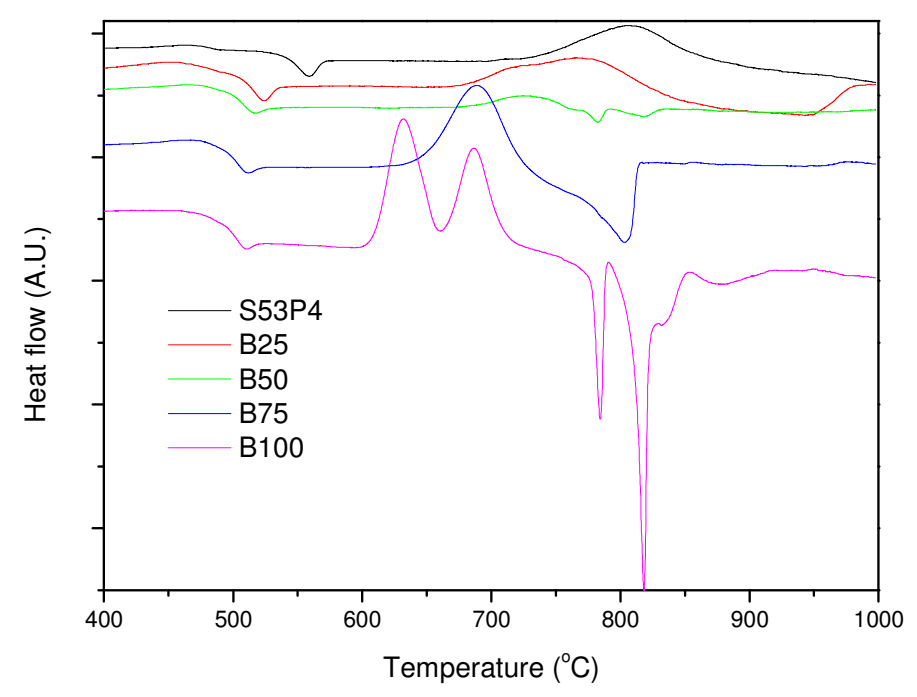

Figure 1: DTA thermogram of the investigated glasses. 


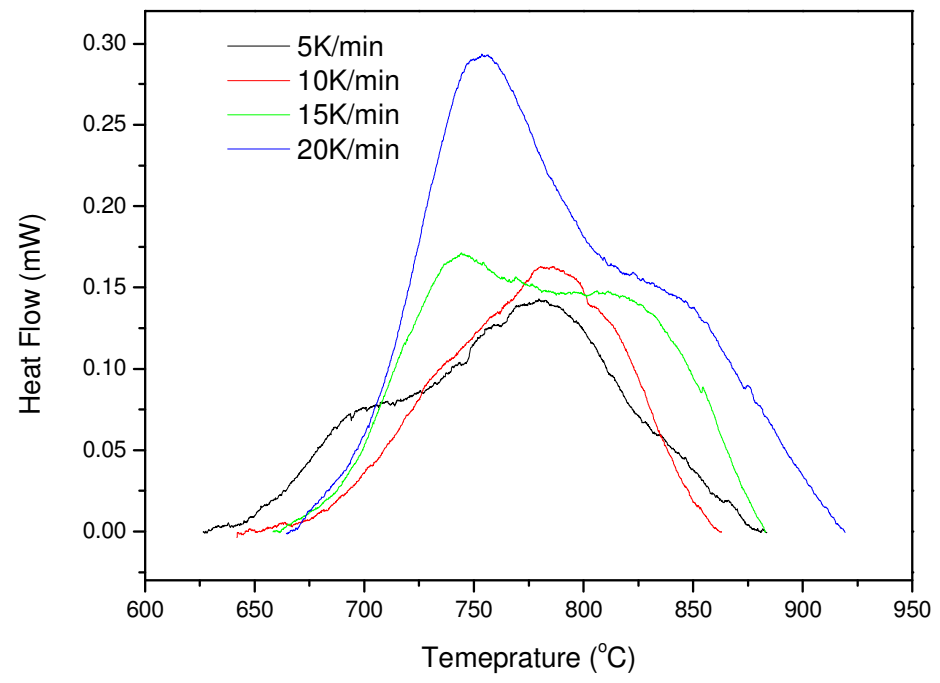

Figure 2: Crystallization peak in glass B25 at various heat rates (from 5 to $20 \mathrm{~K} / \mathrm{min}$ ). This figure show that the crystallization of this glass is highly dependent on the heating rate employed. 


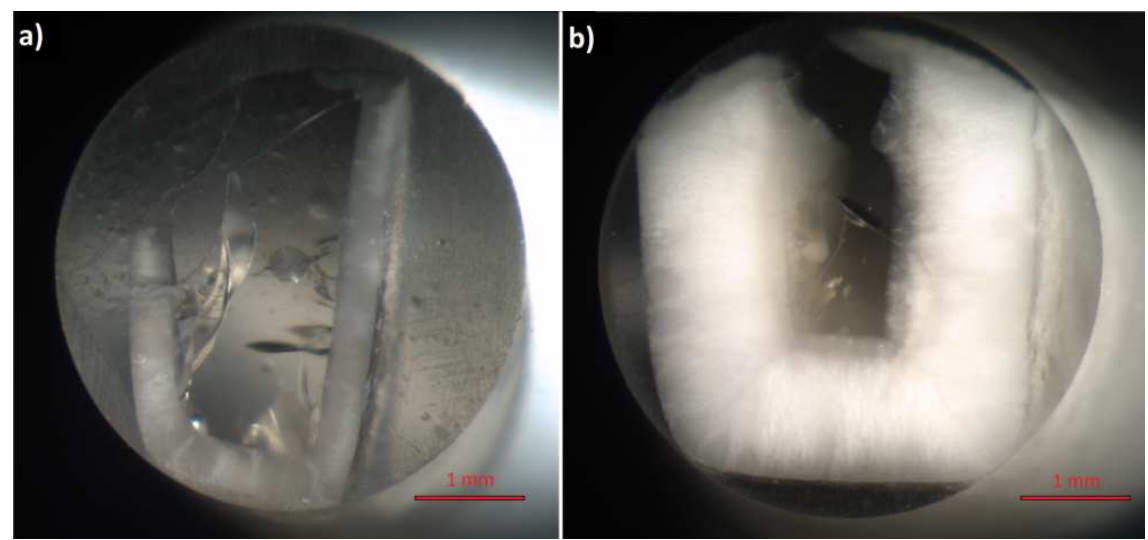

Figure 3: Optical microscope image of glass B100 (embedded in resin) heat treated for $3 \mathrm{~h}$ at $\mathrm{Tp}-60^{\circ} \mathrm{C}$ a) and $\mathrm{Tp}-40^{\circ} \mathrm{C} \mathrm{b}$ ) showing the surface crystallized layer. 


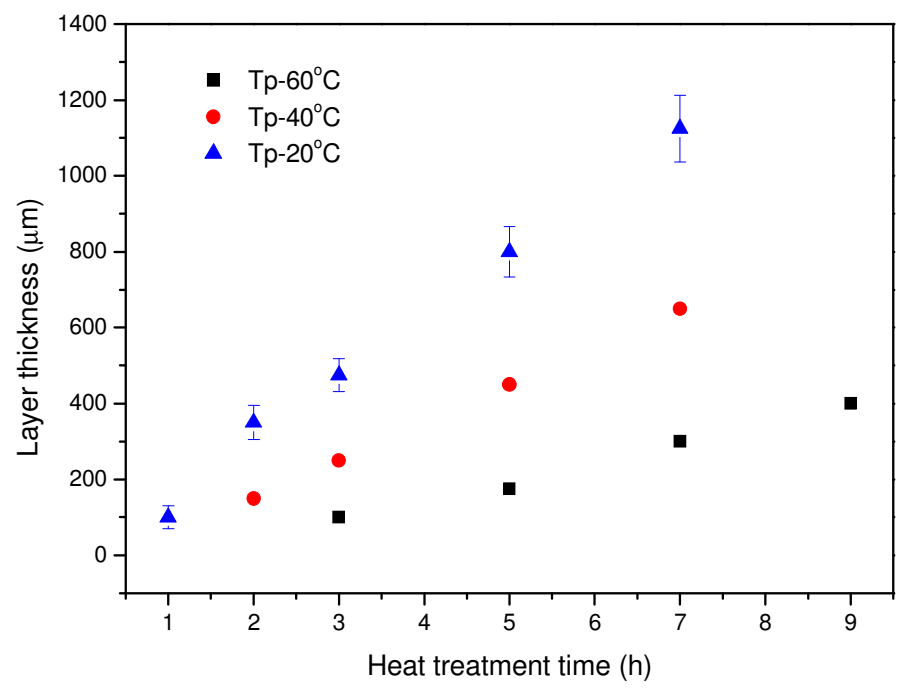

Figure 4: Thickness of the crystallized layer formed as a function of heat treatment temperature. 

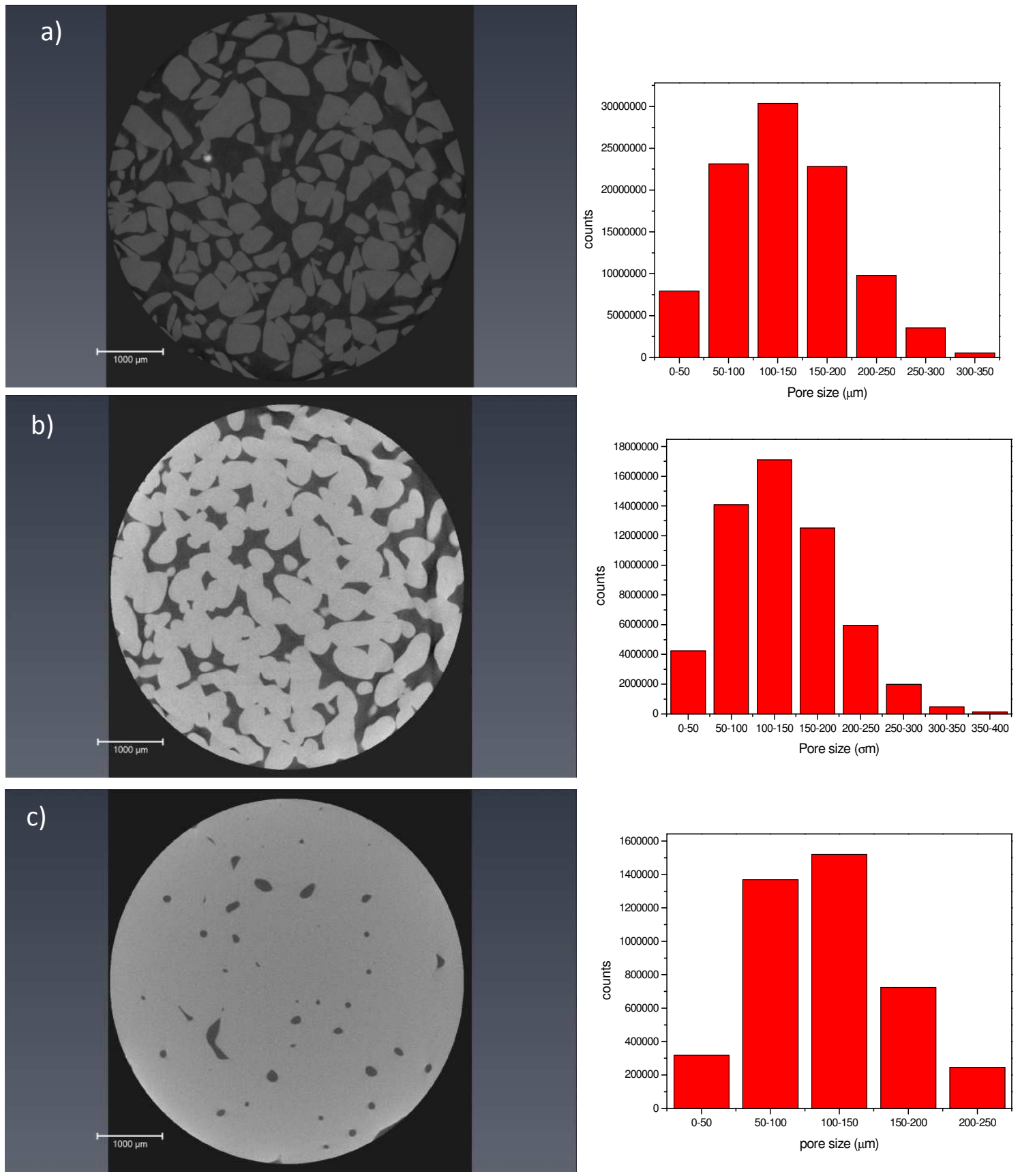

Figure 5: $\mu \mathrm{CT}$ images (left) and pore size distribution (right) of scaffolds obtained from the sintering of B50 glass at $575 \mathrm{a}$ ), $580 \mathrm{~b}$ ) and $590{ }^{\circ} \mathrm{C}$ c). (Bright areas correspond to the glass whereas the dark area to empty spaces) 
a)

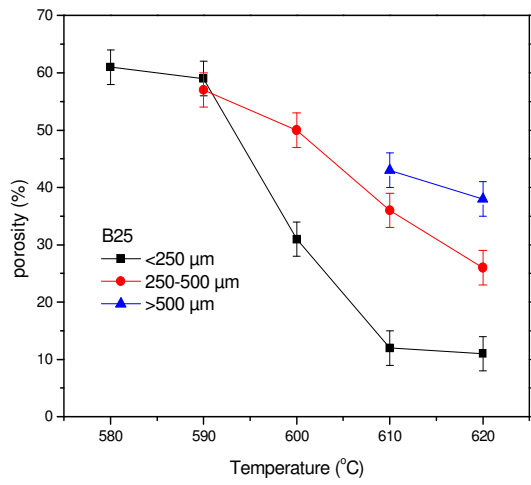

b)

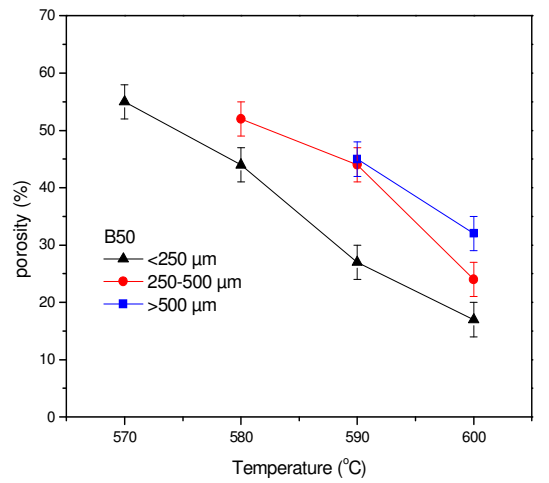

c)

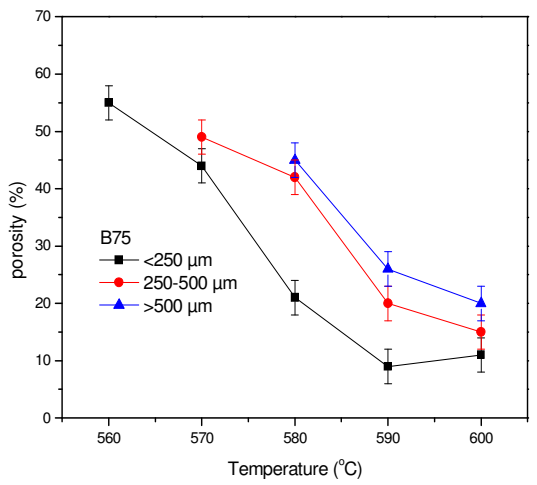

Figure 6: scaffold porosity as a function of sintering temperature 
a)

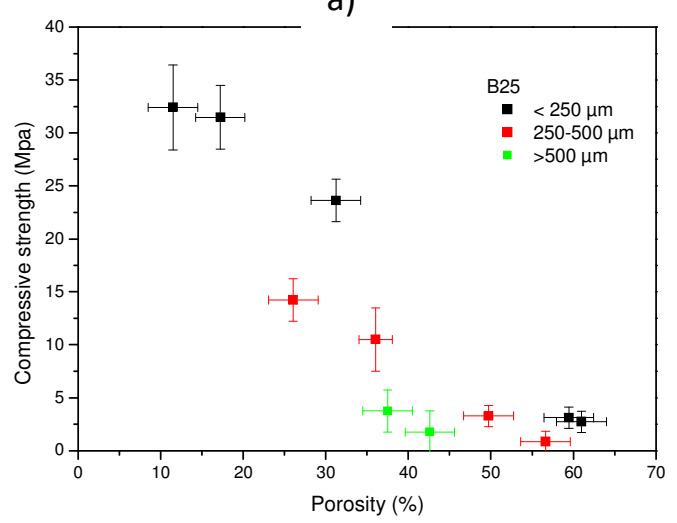

c)

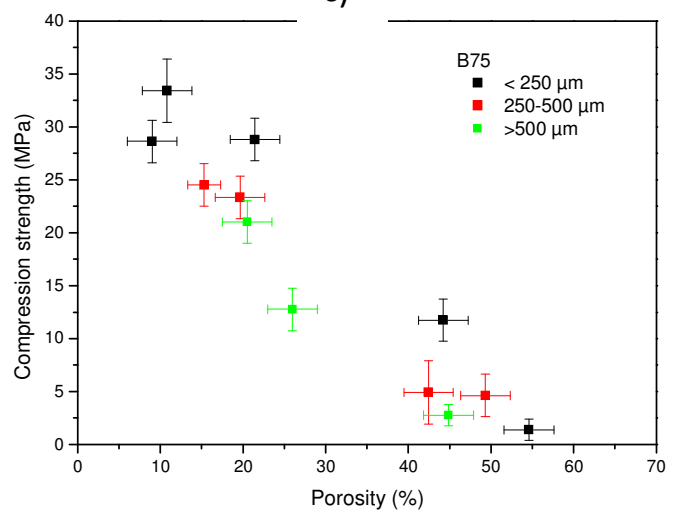

b)

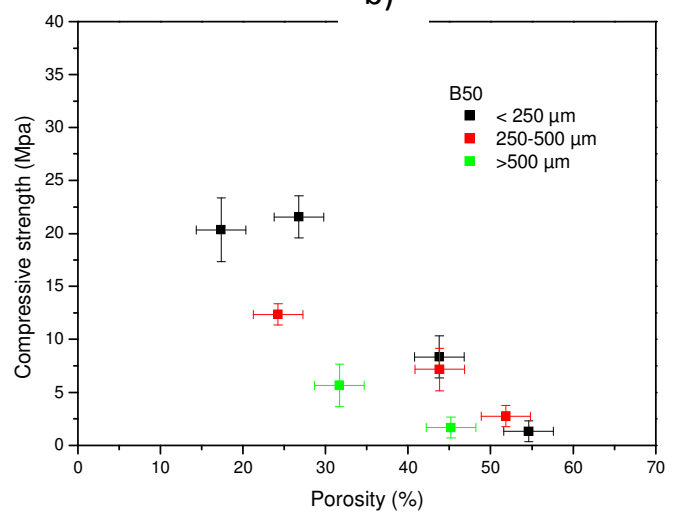

d)

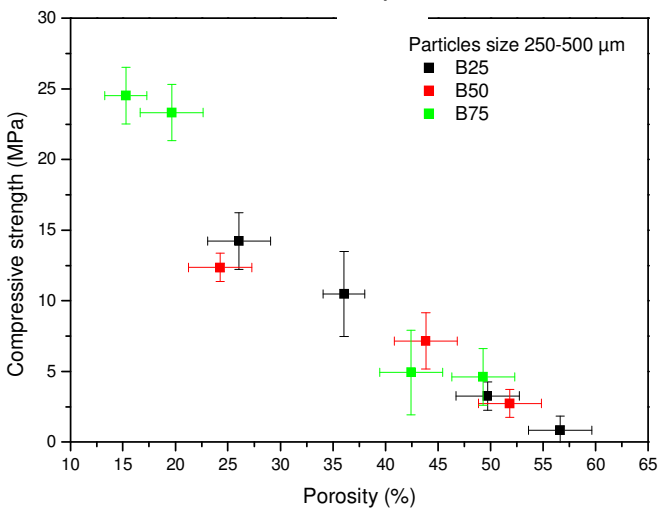

Figure 7: Scaffold compressive strength as a function of scaffolds porosity for glass B25 a), B50 b) and B75 c). The compressive strength of all materials (with particle size $25-500 \mu \mathrm{m}$ ) as a function of porosity is presented in d) showing that the mechanical properties are dictated by the porosity rather than the glass composition. 


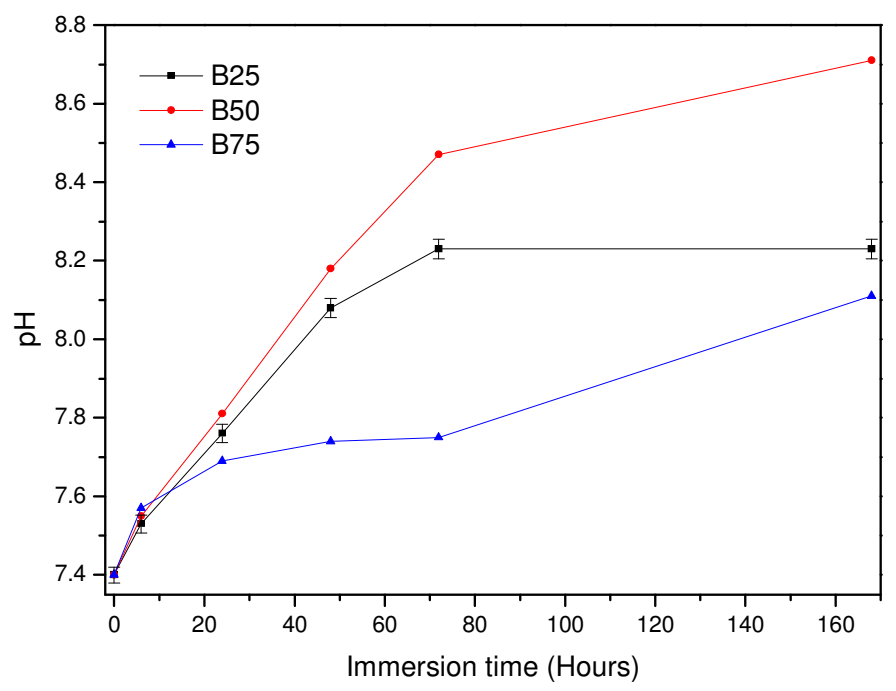

Figure 8: SBF pH change as a function of scaffolds (50\% overall porosity and $100-150 \mu \mathrm{m}$ average pore size) immersion time. 
a)

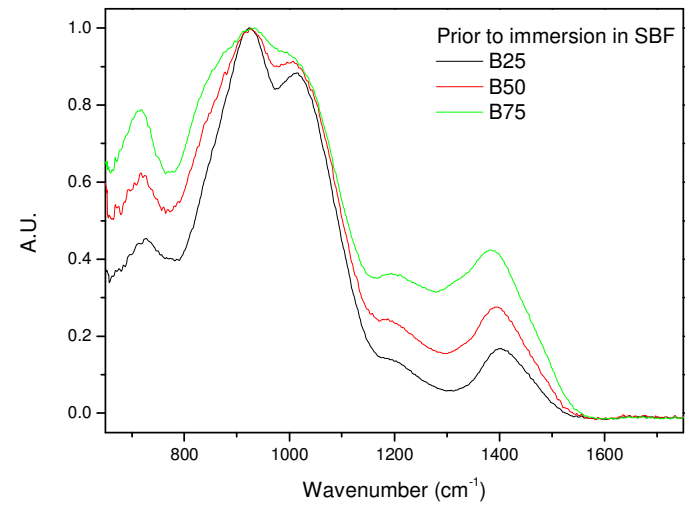

c)

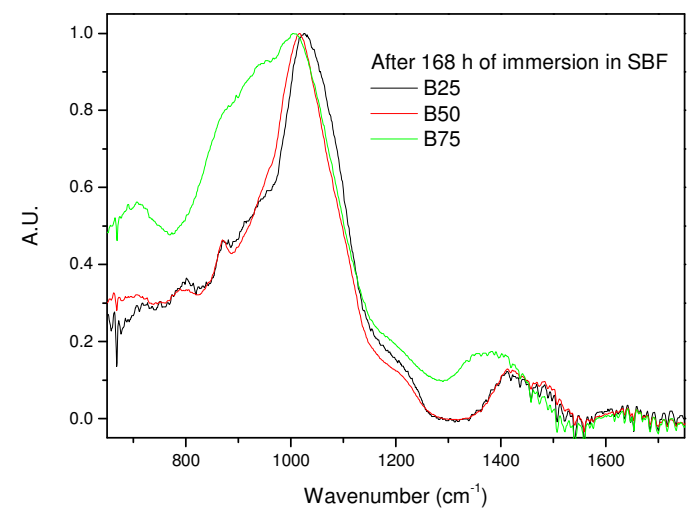

b)

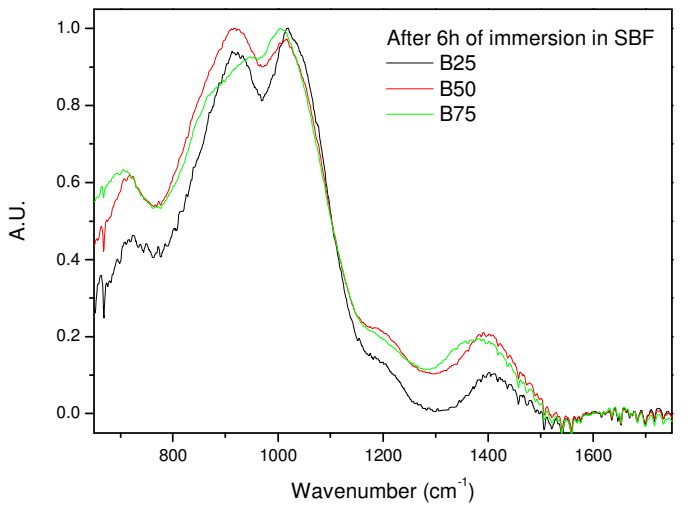

Figure 9: FTIR-ATR spectra at the surface of the scaffold prior a) and after $6 \mathrm{~h} \mathrm{~b}$ ) and $168 \mathrm{~h}$ ) of immersion in SBF. 


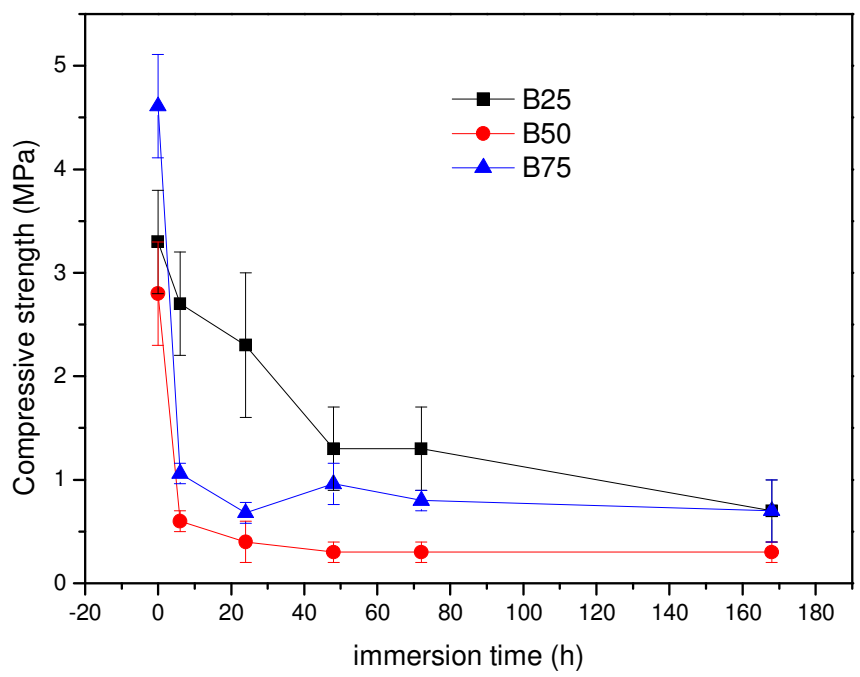

Figure 10: Compressive strength of the scaffolds as a function of immersion time in SBF. 


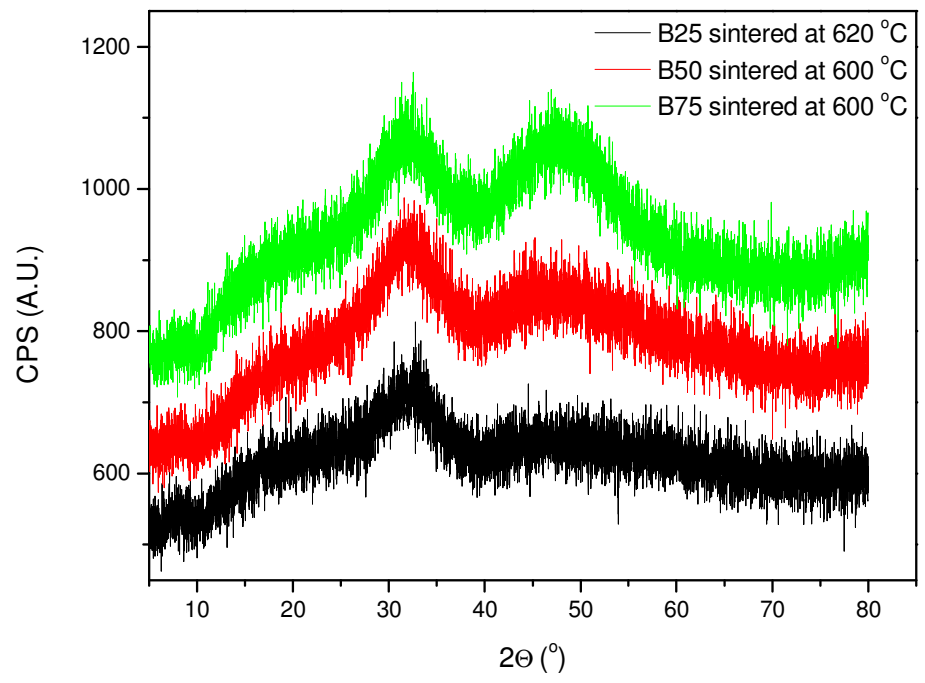

Figure 11: XRD patter of the scaffolds sintered at their respective maximum temperatures. Only broad bands, indicative of the amorphous nature of the materials are visualized. 

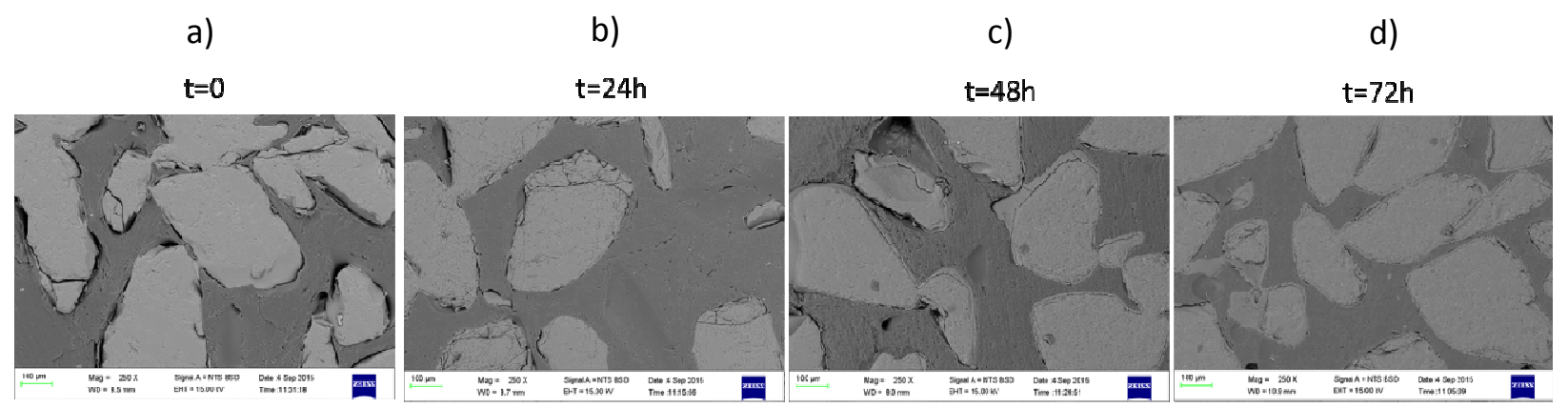

e)

f)

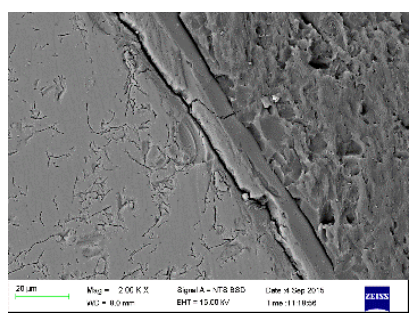

g)

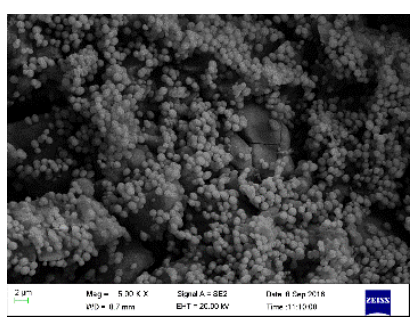

h)
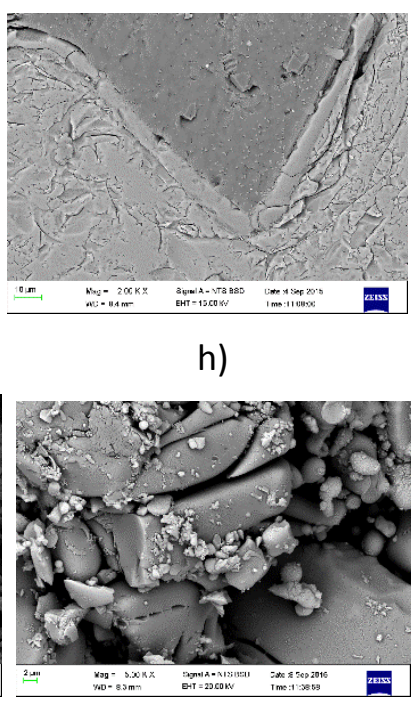

Figure 12: SEM images of the B50 scaffold cross section upon immersion for 24,48 and $72 \mathrm{~h}$ in SBF (a-d). SEM images, with higher magnification of the B50 scaffold cross section upon immersion for 48 and $72 \mathrm{~h}$ (e-f). Top surface images of the scaffolds, showing, at high magnification the Ca-P layer, upon immersion for 48 and $72 \mathrm{~h}(\mathrm{~g}-\mathrm{h})$ 